\title{
Evidence of Fear in Fixed Income and Bourses: A Study on Certain G-7 Economies
}

Shriya Janardan*

\begin{abstract}
The paper aimed to predict the Fear index for certain G7 countries (Canada, France, Germany and Japan) considering the two variables Stock Price (Close) and Bond Yield(LBY). Daily data were analyzed for the period from April 2013 to June 2017. The main purpose was to identify the degree in which fear affecting the stock market percolates to Fixed Income Instruments. Using Panel Data Regression (Fixed Effect Model) the two variables were able to predict the VIX index and the model was found to be robust in nature. The major finding is that Fixed Income and stocks share a negative relationship with VIX (Fear Index).
\end{abstract}

Keywords: Volatility Index, Fixed Income, G-7 Economies, Panel Data Regression, Fear Index

\section{Introduction}

VIX is the Volatility Index created was created by Chicago Board Options Exchange (CBOE) which shows the expected market volatility in the next 30 calendar days. The CBOE Volatility Index (VIX) is known as a fear gauge and it showcases investor consensus views about expected future volatility. A higher level of VIX indicates a higher level of market turmoil. Each country has a fear Indicator or VIX which indicates the volatility for that particular stock market. Fixed Income investments are considered stable

* CHRIST (Deemed to be University), Bangalore, India; shriya.janardan@mba.christuniversity.in 
when compared to Equity holdings. Investors who expect steady income prefer this asset category. In a fixed income investment, an investor lends money to an entity (typically governmental or corporate) who borrows funds for a set period of time at a Fixed or variable interest rate.

Equity or stock represents ownership in a firm. Investors invest in stock for capital appreciation (buy the stock at a low price and sell it at a higher price). But the question is what happens when there is high volatility in the market? Do investors still go-ahead and buy stock or succumb to the fear and sell their stocks causing a massive sell off and thereby increasing the fear in the market. The relationship between VIX and Equity is said to have an inverse relationship. During the period January 1, 2000, to September 28, 2012, VIX moved in the opposite direction of the S\&P 500 about $80 \%$ of the time (www.cboe.com, 2018).

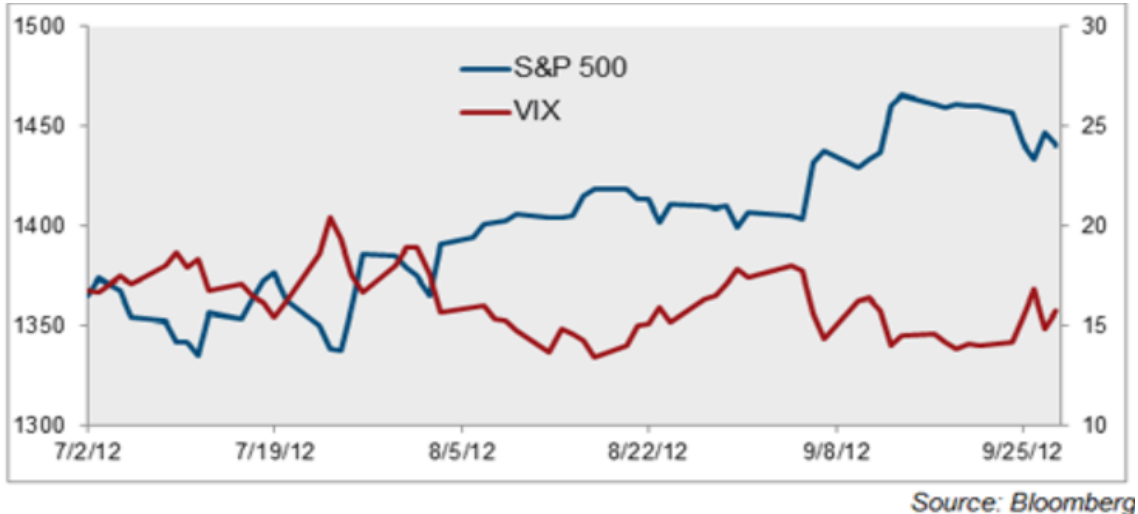

Fig 1 Relationship between the S\&P 500 and VIX

\section{The Inverse Relationship between S\&P 500 and VIX}

During high market volatility, there is a buoyant supply of equity shares due to the massive sell of by investors. Therefore it is important to understand if in this phase the performance of fixed income instrument is superior to equity. The objective of this study is, therefore, to investigate whether the fear in the market affecting the Equity market also affects the returns on fixed income instruments. The combination of variables selected for this paper is 
the daily data for selected countries Canada, France, Germany and Japan.

\section{Literature Review}

Fear influences an investor's decision to either hold or sell a liquid asset. Through multiple decision rounds, it was found that, scared investors sold their assets earlier than those in control conditions (Lee \& Andrade, 2011). Fear plays an important role on how risk is perceived; fearful people followed a pessimistic approach which made them make risk-averse choices (Jennifer, Lerner \& Keltner, 2001). The fear of investors in a market is measured by the Market Volatility Index (VIX), introduced in the year 1993 and known as "the fear gauge" or "the sentiment index". This index measures the implied volatility of options on standard \& poor's 100 stock index. VIX measures the volatility and is conceptually related to yield to maturity as VIX predicts the future volatility implied from the current prices of S\&P 100. One of the attributes of VIX is it is its forward looking characteristics (Whaley, 2008). Giot (2003) analyses VIX and VXN with respect to S\&P 100 and NASDAQ in the short term wherein an increasing VIX could hint a likely increase in stock prices which would signal buy points but in long term, the increase in VIX, S\&P 100 and NASDAQ has generated negative average returns. In a research conducted to understand the relationship between technical analysis and VIX, it was found that trading signals calculated with the help of VIX generated significant profits that were in excess of the profits from the traditional computation (Kozyra \& Lento, 2011). It was observed that from 1993/95 to 2002 time interval, VXO and VXN appeared to be partly forecasts of future volatility and partly fear gauges. The pertinent issue was whether the VXO and VXN were measuring the fear or just forecasts of future volatility (Arak \& Naranchimeg, 2006). The recent methodology employed by $\mathrm{CBOE}$ includes the principle of Extreme Value theory, arguing for the central role of jump tail risk in explaining large equity and variance Risk premium (Bollerslev, 2011).

The relationship between VIX and S\&P 500 volatility is observed to have a nonlinear relationship and can be used as a hedging tool by adjusting the portfolio volatility in a nonlinear manner with respect 
to the movement in VIX (Russon \& Vakil, 2017). Thielen (2016) studied the relationship between VIX and stock market Index return in the US and Germany and found that VIX and stock market index returns had an inverse relationship and VIX could also be used as a trade indicator. With respect to VIX and trading volume, it was seen that higher level VIX is associated with substantial variability in trading volume. Moreover, the effect of noise traders builds in liquidity in the market which proffers extra opportunities for investors to time their trade as the volatility of liquidity increases. These two factors decrease the rational investors' required return (Lei, So, \& Zou, 2012). In a study of lag between S\&P 500, Credit Default Swap Index and VIX, VIX and CDX showed a positive relationship and VIX and S\&P 500 showed a negative relationship (Winberg \& Rugas, 2015). Badshah (2018) throws light on the idea of "volatility spillover from the fear index to developed and emerging markets" and shows how developed and emerging markets are highly correlated with the fear index, and hence, shows how the fear index acts as a driver of correlation dynamics in the emerging markets. During the period 1999-2009, it was observed that during stable market regimes, VIX overestimated the S\&P index volatility and during high volatility period, it underestimated S\&P 500 (Vodenska \& Chambers, 2013). A similar result was found by (Chow, Jiang, \& Li, 2014) where VIX understated the true volatility and the estimation errors considerably enlarged during volatile markets. With respect to the fear index, a spillover effect was also spotted from the US market to other markets (Tsai, 2014). During the period of crisis, the return spillovers were mainly influenced by the spillover effect from stock and bond returns which got stronger throughout different stages of the financial crisis (Eraslan, 2017). In an examination of "pricing of aggregate volatility risk in the cross-section of stock returns", it was seen that stocks with higher sensitivity to innovations in aggregate volatility have low average returns (Ang, Hodrick, Xing \& Zhang, 2006).

It is imperative to understand the association between VIX, stock and Bond. During the period of uncertainty, Stivers \& Sun (2002) found that during periods of lower stock market uncertainty, stock and bond returns tend to move substantially together. However, during periods of high stock market uncertainty, stock and bond 
returns tend to show little relation or even an inverse relation. A trend component into a smooth transition regression (STR) model was introduced to evaluate the trends in stock and Bond movements and the results indicated a significant decreasing trend in stock-bond correlations for many advanced safer countries. Furthermore, in riskier Eurozone countries during the beginning of the Euro crisis, a significant increase in stock-bond correlations was found (Harumi, 2015). In 17 Euro countries, it was found that VIX acts as a key determinant in stock and Bond Comovements(Skintzi, 2017). Chiang, Li, \& Yang (2015) investigated the dynamic correlations of stock-bond returns for six advanced markets and found a negative stock-bond correlation with stock market uncertainty which was measured by the conditional variance and the implied volatility of the S\&P 500 index. However, a positive stock-bond relation was found with respect to bond market uncertainty in the G7 countries pertaining to the relationship between stock and bond movements which was measured by the conditional variance of bond returns. It was noticed the correlation between changes in stock prices and bond yields could depend on the time scale and differ from country to country. Furthermore, using wavelet analysis it was revealed that changes in bond yields and stock prices do not move together in most G7 countries, except in Japan (Kim \& In, 2007).

The correlation between Equity and Bond yields play a vital role in portfolio asset allocation decisions; a positive correlation was derived between equity and stocks in the past 15 years and during the period of economic uncertainty, a consistent positive correlation was observed (Rankin \& Idil, 2014). The endogenous correlation between stock and bonds has been explained by using the Asset Pricing Model to find the fundamental drivers that affect the pricing of stock and bonds for post-war G7 countries. The result showed that the factor increasing the correlation between stocks and bonds was the volatility in the Real Interest Rates (d'Addona \& Kind, 2006).

In emerging markets, Stock and Bond correlation change with time horizon whereas in the short horizon, the factor which influences stock and bond correlation is monetary policy stance and in the long term, the influencing factors are inflation and stock market 
uncertainty (Dimic, Kiviaho, Piljak \& Äijö, 2014). Through a dynamic factor model, the study of economic sources affecting the stock and bond co-movements was researched and it was identified that the best factors which explained the correlations and covariance were the non-macro variables, especially stock and bond market illiquidity factors. It was observed that in the case of bonds, a large role was played by fundamental factors, but for stocks, the liquidity factors played a key role (Baele, Bekaert \& Inghelbrecht, 2010). They questioned the correlation of variation in stock and bond returns with time and argued that a successful explanation must be provided in the time-varying behaviour of real rates. Vychytilova (2015) aimed at linking the commodity futures, U.S. Treasury bond yields and equity market to understand volatility returns and detect statistical correlation for Crisis and Non-Crisis collected over the period January $4^{\text {th }}$ 1999-April 01 $1^{\text {st }}$ 2015 and found that VIX and Treasury Bond yields have a negative correlation. Furthermore, it was seen that commodity futures and VIX also share a negative correlation. Indian research group (Ghosh, 2017; Ghosh, Le Roux, \& Ianole, 2017; Ghosh, 2017) too have worked on BRICS and India in depth to find traces of fear, transfer of assets based on fear (equity to gold) and more interestingly 'reverse anchoring'.

\section{Research Methodology}

\subsection{Variables}

The total number of observations contained in our dataset is 12624 , collected for the period between 12th April 2013 and 30th June 2017 for all the targeted countries (Canada, France, Germany and Japan). The dependent variable is VIX. Here, an attempt is being made to predict VIX with the help of External Variables like SP (stock price) and BY(Bond yield). The logarithm of BY has been taken to reduce the standard error.

\subsection{Panel Data Regression (Fixed Effect)}

To form a Panel Data Regression, time series and cross-sectional data are combined where similar universe of countries or companies are recorded with time and phenomena. Sometimes the presence of lagged dependent variables too becomes an accurate 
indicator. The panel data regression, both on fixed and random effect has the same basic equation to follow:

$y_{i t}=a+b x_{i t}+\epsilon_{i t}$

Where $y$ and $x$ are variables, " $a$ " and " $b$ " are coefficients and $i, t$ are indices for individuals and time. $\epsilon$ as an error term is the only part that changes between a fixed effect and random effect. For fixed effect, it varies in a non-stochastic manner with reference to either i or $t$, where as in random effects, it varies in a stochastic manner with reference to either $i$ or $t$.

Table 1: Estimation Output

\begin{tabular}{lllll}
\hline Variable & Coefficient & Std.Error & T-statistic & Prob \\
\hline C & 100.7854 & 9.984891 & 10.0948 & \\
LSP & -8.2491 & 1.089081 & -7.574451 & 0.0000 \\
BY & -5.175 & 0.252064 & -20.53056 & 0.0000 \\
\hline
\end{tabular}

Table 1.2 Robustness Criteria

\begin{tabular}{ll}
\hline Akaike Info criterion & 5.2691 \\
Schwarz Criterion & 6.8629 \\
Hannan-Quinn Crit. & 5.8326 \\
\hline
\end{tabular}

Modelling Volatility; Source: Compiled by author in EViews 10

\subsection{Probability Statistics}

Testing the correlation between SP and VIX and linking the objective with the hypothesis.

$\mathrm{H}_{0}$ : SP cannot predict VIX

$\mathrm{H}_{1}$ : SP can predict VIX

The probability value for SP is 0 . Null hypothesis has been rejected; the alternate hypothesis is accepted. Therefore, SP can predict VIX. Next, for testing the correlation between BY and VIX and linking the objective with the hypothesis, the following formulations are made.

$\mathrm{H}_{0}$ : BY cannot Predict VIX

$\mathrm{H}_{1}$ : BY can predict VIX. 
The probability value for BY is 0 . Null hypothesis has been rejected; the alternate hypothesis is accepted. Therefore BY can predict VIX.

Both LSP and BY have been found to be able enough to predict VIX, as a whole (Panel).

\subsection{Robustness of the Model}

AIC, SC and HQ consider the log likelihood factors and successively define a definite penalty on those depending on the variables under estimation. Here, Akaike Info criterion, Schwarz criterion and Hannan-Quinn criterion are in the range of 5-8 (less than 10). Therefore, the model is accurate and sustainable, in other words, the most important measures were found to satisfy the robustness conditions.

Equation Representation

$V I X=100.7853-8.2491 \times L S P-5.1750 \times B Y$

The equation gives us an understanding of the relationship between VIX, Bond Yield and stock. The analysis of the equation reveals that both stocks and Bonds have a negative correlation with VIX. This shows that when the fear in the market increases both stock prices and bond yield decreases.

\section{Conclusion}

This paper is an attempt to analyse VIX (Fear index) using Stock price (close) and Bond yield. Its focus is on capturing the link between the Fear Index and the behaviour of the two asset classes in the market. Using Panel Data regression (Fixed Effect Model), it was seen that stock prices and bond yield were able to predict VIX for the selected countries and were robust in nature (Canada, France, Germany and Japan). It is important to note that stock price and Bond yield both have negative signed coefficients, signifying that the Bond Yield and the Stock price goes down with increasing VIX. This implies that the two are inversely proportional to the implied volatility factors for the selected countries. However, the stock price (close) has a higher intensity of impact on VIX when compared to Bond Yield (LBY). In Japan, during the period JuneJuly 2016, Nikkei Volatility Index was in the range of 25-29. 
Generally, this indicates a high fear in the market; the Nikkei had dropped by $6 \%$ and the bond yield fell below zero. The reason for the negative bond yield was due to negative interest rates in the country which was facing ultra-low inflation.

Thus, the results of this paper could influence an investor's ability to predict the fear index (VIX)/market fear with the help of Bond yield (LBY) and Stock price (Close) and can also enhance the investor's decision making ability in shifting their investment from Equity to Fixed income during the period of uncertainty in the market by understanding their behavior.

\section{Scope for Further Research}

This research can also be performed using different models like GMM (Generalized Dynamic Model) and neural network. The research can further be performed on the remaining G7 countries.

\section{References}

Ang, A., Hodrick, R. J., Xing, Y., \& Zhang, X. (2006). The cross-section of volatility and expected returns. Journal of Finance, 61(1), 259-299. https://doi.org/10.1111/j.1540-6261.2006.00836.x

Arak, M., \& Naranchimeg, M. (2006). The VIX and VXN volatility measures: Fear gauges or forecasts? Derivatives Use, Trading $\mathcal{E}$ Regulation, 12(1/2), 14-27. https://doi.org/ 10.1057/ palgrave. dutr.1840040

Badshah, I. U. (2018). Volatility spillover from the fear index to developed and emerging markets. Emerging Markets Finance and Trade, 54(1), 2740. https:/ / doi.org/10.1080/1540496X.2016.1220294

Baele, L., Bekaert, G., \& Inghelbrecht, K. (2010). The determinants of stock and bond return comovements. Review of Financial Studies, 23(6), 23742428. https://doi.org/10.1093/rfs/hhq014

Chiang, T. C., Li, J., \& Yang, S. Y. (2015). Dynamic stock-bond return correlations and financial market uncertainty. Review of Quantitative Finance and Accounting, 45(1), 59-88. https://doi.org/10.1007/s11156013-0430-4

Chow, V., Jiang, W., \& Li, J. (Victoria). (2014). Does VIX Truly Measure Return Volatility? SSRN, 1-35. https://doi.org/10.2139/ssrn.2489345

d'Addona, S., \& Kind, A. H. (2006). International stock-bond correlations in a simple affine asset pricing model. Journal of Banking and Finance, 30(10), 2747-2765. https:// doi.org/10.1016/j.jbankfin.2005.10.007 
Dimic, N., Kiviaho, J., Piljak, V., \& Äijö, J. (2014). Impact of Financial Market Uncertainty and Macroeconomic Factors on Stock-Bond Correlation in Emerging Markets. Department of Accounting and Finance University of Vaasa.

G. Russon, M., \& F. Vakil, A. (2017). On the non-linear relationship between VIX and realized SP500 volatility. Investment Management and Financial Innovations, 14(2), 200-206. https://doi.org/ 10.21511/ imfi.14(2-1).2017.05

Ghosh, B. (2017). FRA-CDS-VDAX based credit crash model: A German conundrum. International Journal of Economic Research, 14(8), 221-228.

Ghosh, B. (2017). Quest for Behavioural Traces the Neural Way: A Study on BSE 100 along with its Oscillators. Indian Journal of Research in Capital Markets, 4(1), 19-25.

Ghosh, B., Le Roux, C., \& Ianole, R. (2017). Fear estimation-evidence from BRICS and UK. International Journal of Applied Business and Economic Research, 15(4), 195-207.

Giot, P. (2003). Implied Volatility Indices as Leading Indicators of Stock Index Returns? SSRN, 50(2002). https://doi.org/10.2139/ssrn.371461

Harumi, O. (2015). Trends in Stock-Bond Correlations. RIETI Discussion Paper Series 15-E-115 Trends in Stock-Bond Correlations.

Jennifer s Lerner, D., \& Keltner. (2001). Fear anger worry. Journal of Personality and Social Psychology, 81 Number, 146-159.

Kim, S., \& In, F. (2007). On the relationship between changes in stock prices and bond yields in the G7 countries: Wavelet analysis. Journal of International Financial Markets, Institutions and Money, 17(2), 167-179. https:// doi.org/10.1016/j.intfin.2005.10.004

Kozyra, J., \& Lento, C. (2011). Using vix data to enhance technical trading signals. Applied Economics Letters, 18(14), 1367-1370. https:// doi.org/ 10.1080/13504851.2010.537623

Lee, C. J., \& Andrade, E. B. (2011). Fear, social projection, and financial decision making. Journal of Marketing Research, 48(SPL), S121-S129. https:// doi.org/10.1509/jmkr.48.SPL.S121

Lei, V. U. T., So, S. M. S., \& Zou, M. (2012). Investor Sentiment relationship between vix and trading volume. SSRN, 5(4), 114-121. https://doi.org/10.2139/ssrn.2136802

Rankin, E., \& Shah Idil, M. (2014). A century of stock-bond correlations. Bulletin of the Reserve Bank of Australia, September, 67-74.।

Eraslan, S., \& Ali, F. (2017). Financial crises and the dynamic linkages between stock and bond returns. Bundesbank Discussion Paper No 17/2017. Deutsche Bundesbank.

Skintzi, V. D. (2019). Determinants of stock-bond market comovement in the Eurozoneunder model uncertainty. International Review of Financial Analysis, 61, 20-28. 
Stivers, C. T., \& Sun, L. (2002). Stock market uncertainty and the relation between stock and bond returns. Working Paper, (March).

Thielen, B. (2016). Volatility and stock market returns. Tilburg University Faculty of Economics and Business Administration Department of Financ, 38.

Bollerslev, T. \& Todorov, V. (2011). Tails, fears, and risk premia. The Journal of Finance, 66(6), 2165-2211.

Tsai, I. C. (2014). Spillover of fear: Evidence from the stock markets of five developed countries. International Review of Financial Analysis, 33, 281288. https://doi.org/10.1016/j.irfa.2014.03.007

Vodenska, I., \& Chambers, W. J. (2013). Understanding the Relationship between VIX and the S\&P 500 Index Volatility. SSRN, (i). https:// doi.org/10.2139/ssrn.2311964

Vychytilova, J. (2015). Linkages among U.S. Treasury Bond Yields, commodity futures and stock market implied volatility: New Nonparametric Evidence. Journal of Competitiveness, 7(3), 143-158. https:// doi.org/10.7441/joc.2015.03.10

Whaley, R. E. (2008). Understanding VIX. SSRN, (615), 13. https:// doi.org/ 10.2139/ssrn.1296743

Winberg, A., \& Rugas, N. (2015). A study on the relation between VIX, S\&P500 and the CDX-index. University of Gothenberg School of Business,economics and Lows. 